Jurnal Indonesia Sosial Teknologi: p-ISSN: 2723 - 6609

e-ISSN : 2745-5254

Vol. 2, No. 5 Mei 2021

\title{
ANALISIS METODE PERHITUNGAN HARGA POKOK PRODUKSI PADA HOME INDUSTRI SEPATU KULIT
}

\section{Lailatun Nafisa}

Prodi Akuntansi STIE Yadika Bangil, Indonesia

Email: nafisa.rubai@gmail.com

\section{Abstract}

At this time, Indonesia is facing an era of globalization, where technology is developing rapidly, as well as the very fast development of today's business world. Every company or home industry must be able to compete in order to survive, so the company must have long-term competitiveness as well as short-term competitiveness of the products it produces. This study aims to determine the cost of goods manufactured using the variable costing method and the full costing method, determine the selling price so that it is not too high and not too low, to determine whether consumers prefer price or product quality. The method used in this observation is qualitative with the interview method, where the subject / informant is the owner and customer, observation and documentation of the Three Star's shop owner. The results showed that with these two methods, the researcher can suggest to the owner in calculating the cost of products to use the variable costing method rather than using the full costing method, because the data shows that the cost's calculation of goods manufactured using the variable costing method is lower than using the full costing method. And by using variable costing the selling price is lower than the full costing method. Many customers are more concerned with product quality than product prices, because with high product quality, customers get more satisfaction. Instead they buy cheaply but many times and get low quality.

Keyword: Cost of goods manufactured, Variable Costing, Full Costing, Selling Price, and Product Quality.

\footnotetext{
Abstrak

Pada masa sekarang ini Indonesia sedang menghadapi era globalisasi, dimana teknologi sedang berkembang dengan pesat, begitupun perkembangan dengan dunia usaha saat ini sangat pesat. Setiap perusahaan maupun industri rumahan harus mampu bersaing demi bisa tetap bertahan, maka perusahaan harus memiliki daya saing jangka panjang maupun daya saing jangka pendek atas produk-produk yang dihasilkan. Tujuan dari penelitian ini adalah untuk mengetahui penentuan harga pokok produksi menggunakan metode variable costing dan metode full costing, menentukan harga jual agar tidak terlalu tinggi dan tidak terlalu rendah, mengetahui apakah konsumen lebih memilih harga ataukah kualitas produk. Metode yang digunakan dalam pengamatan ini adalah kualitatif dengan metode wawancara, dimana subjek / informannya adalah pemilik dan pelanggan, observasi dan dokumentasi pada pemilik toko Three Star's. Hasil penelitian diperoleh bahwa dengan adanya ke dua metode tersebut maka peneliti dapat menyarankan kepada
} 
pemilik dalam menghitung harga pokok produk untuk lebih menggunakan metode variable costing dari pada menggunakan metode full costing, karena dari hasil data bahwa perhitungan harga pokok produksi menggunakan metode variable costing lebih rendah dibanding menggunakan metode full costing. Dan dengan menggunakan variable costing harga jual lebih rendah dibanding dengan metode full costing. Banyak para pelanggan yang lebih mementingkan kualitas produk dibandingkan dengan harga produk, karena dengan kualitas produk yang tinggi maka para pelanggan mendapatkan kepuasan yang lebih. Dari pada mereka membeli dengan harga murah tetapi berkali-kali dan mendapatkan kualitas yang rendah.

Kata kunci: Harga pokok produksi; Variable Costing, Full Costing; Harga jual; dan Kualitas Produk.

\section{Pendahuluan}

Pada masa sekarang ini Indonesia sedang menghadapi era globalisasi, dimana teknologi sedang berkembang dengan pesat, begitupun perkembangan dengan dunia usaha saat ini sangat pesat. Setiap perusahaan maupun industri rumahan harus mampu bersaing demi bisa tetap bertahan, maka perusahaan harus memiliki daya saing jangka panjang maupun daya saing jangka pendek atas produk-produk yang dihasilkan. Perkembangan industri pembuatan sepatu diikuti dengan meningkatnya jumlah produk lokal, yang berkualitas dan mengalami perkembangan pesat selama beberapa dekade terakhir ini. Dengan adanya persaingan yang sangat ketat, maka perusahaan dituntut untuk selalu tepat dalam pengambilan keputusan demi menjaga kelangsungan hidup perusahaan agar dapat bertahan. Perusahaan maupun industri rumahan kini berorientasi pada peningkatan laba yang optimal, sebagai tujuan pengembangan usahanya.

Harga jual suatu produk merupakan salah satu faktor penting disamping faktorfaktor lain, yang harus diperhatikan dalam bisnis perusahaan dagang maupun perusahaan manufaktur (Mulyanto Veri Arti, 2017). Seorang pelanggan atau konsumen seringkali mempertimbangkan harga dalam membuat keputusan apakah ia akan membeli suatu produk atau tidak (Philip \& Keller, 2012). Membagi proses pengambilan keputusan menjadi lima tahap, yaitu : pengenalan masalah, pencarian informasi, evaluasi alternatif, keputusan pembelian dan perilaku pascapembelian. Walaupun sebenarnya kualitas lebih diunggulkan dari pada harga, tetapi tidak dipungkiri bahwa harga sangat berperan penting dalam proses pembuatan keputusan pembelian barang oleh konsumen. Menurut (Buchari, 2011) penetapan harga adalah keputusan mengenai harga-harga yang akan di ikuti dalam jangka waktu tertentu. Sedangkan menurut (Kotler \& Amstrong, 2012) kualitas produk adalah kemampuan sebuah produk dalam memperagakan fungsinya, hal ini termasuk keseluruhan durabilitas, reliabilitas, ketetapan kemudahan pengoperasian dan reparasi produk, juga atribut produk lainnya.

Kebijakan harga jual produk dan biaya akan selalu berubah-ubah sesuai dengan perubahan biaya produk dan kondisi pasar (Fauzan, 2019). Sebagai pelaku usaha, perusahaan harus mampu memahami keinginan yang dibutuhkan konsumen, tentang 
produk agar konsumen merasa puas dan tidak beralih ke produk lain (Hendy, 2019). Begitu juga dengan Usaha Dagang Three Star's milik Bapak Tri Mulyo, yang memproduksi sepatu kulit, maupun sepatu semi kulit, sepatu sekolah, sepatu para pekerja kontraktor maupun pekerja kantor dan juga sepatu fashion / sepatu yang sesuai dengan pesanan / sesuai selera dari para konsumen.

Three Star's adalah toko sepatu yang sangat diminati oleh para pelanggannya, oleh karena itu Bapak Tri Mulyo tidak boleh salah dalam menentukan harga pokok produksi sepatu dengan harga jual sepatu. Jika Bapak Tri salah dalam memperhitungkan harga pokok produksi maka akan berpengaruh terhadap harga jual sepatu (Fitria, 2018). Penentuan harga pokok produksi merupakan hal yang sangat penting, karena informasi dari harga pokok produksi adalah menentukan harga jual produk, serta penentuan harga pokok persediaan jadi dan produk dalam proses yang akan disajikan dalam neraca. Di dalam penentuan harga pokok produksi, informasi yang dibutuhkan adalah informasi mengenai biaya bahan baku, biaya tenaga kerja, dan biaya overhead pabrik (Dewi, 2014). Dari tiga kegiatan tersebut harus ditentukan dengan cermat baik dalam pencatatan maupun penggolongannya, agar informasi tersebut dapat diandalkan baik untuk penentuan harga jual produk maupun untuk perhitungan laba rugi.

Harga pokok produk mempengaruhi perhitungan laba rugi, jika penentuan harga pokok produksi kurang teliti, maka akan terjadi kesalahan dalam penentuan laba rugi yang diperoleh (Rizqi, 2018). Dalam memperhitungkan unsur-unsur biaya kedalam harga pokok produksi, terdapat dua metode yaitu metode full costing dan metode variable costing. Full costing adalah metode yang menentukan harga pokok produksi yang membebankan seluruh biaya produksi, baik biaya tetap maupun biaya variable ke dalam produk. Sedangkan variable costing merupakan metode penentuan harga pokok produksi yang hanya membebankan biaya-biaya produksi variable saja ke dalam harga pokok produk (Mulyadi, 2015). Disini peneliti ingin membantu toko Three Star's mencoba menerapkan metode full costing dan metode variable costing, supaya sedikit membantu pemilik dalam menentukan harga pokok produksi pada home industry Three Star's.

\section{Metode Penelitian}

Penelitian ini menggunakan pendekatan fenomenologis, (Bungin, 2019) pendekatan fenomenologis juga dapat dipahami sebagai suatu upaya untuk mengungkap ataupun membongkar sesuatu yang tersembunyi dari dalam diri pelaku.

Penelitian ini mengambil tempat di Desa Pandaan yang terletak di Jl. Jaksa Agung Suprapto RT. 01 RW. 01 Kedondong Sumbergedang. Pemilihan lokasi tersebut dengan pertimbangan bahwa di desa Pandaan banyak terdapat home industry maupun industry sepatu.

Dalam penelitian ini menggunakan wawancara langsung dengan berbagai pihak yang terkait, diantaranya adalah pemilik dan pelanggan dari Toko Three Star's. Dan juga peneliti melakukan observasi dan dokumentasi, metode ini digunakan untuk 
memperoleh data yang diperlukan berkaitan dengan masalah yang diteliti. Adapun Informan sebagai berikut:

Tabel 1. Informan

\begin{tabular}{ccc}
\hline No. & Nama Informan & Pekerjaan \\
\hline 1. & Bapak Tri Mulyo & Pemilik Toko Three Star's \\
\hline 2. & Bapak Khoirul & Pelanggan \\
\hline 3. & Ibu Lutfiati & Pelanggan \\
\hline 4. & Bapak Arifki & Pelanggan \\
\hline \multicolumn{2}{l}{ Sumber : Data Pelanggan (Home Industry sepatu kulit 2021) }
\end{tabular}

Data yang telah dikumpulkan baik dari wawancara, observasi maupun dokumentasi, selanjutnya dianalisa secara kualitatif. Untuk melakukan penelitian ini diperlukan beberapa tahapan proses penelitian antara lain tahap persiapan penelitian dan tahap pelaksanaan penelitian untuk mendapatkan data yang diperlukan, pelaksanaan analisis berdasarkan pendekatan yang digunakan hingga mendapatkan hasil yang diinginkan sesuai dengan tujuan penelitian.

\section{Hasil dan Pembahasan}

Hasil perhitungan harga pokok produksi dengan metode Variable Costing

1. Produk Sepatu Kerja dengan hasil 110 pcs

\begin{tabular}{lc}
\hline \multicolumn{1}{c}{ Nama Akun } & Dalam Satuan (Rp) \\
\hline Biaya Bahan Baku & 8.000 .000 \\
\hline Tenaga Kerja Langsung & 500.000 \\
\hline Overhead Pabrik Variable & 2.000 .000 \\
\hline Kos Produksi & $\mathbf{1 0 . 5 0 0 . 0 0 0}$ \\
\hline Harga pokok per unit & 95.500 (dibulatkan) \\
\hline Sumber : Data Olahan (home industry sepatu kulit 2021)
\end{tabular}

2. Produk Sepatu Sekolah dengan hasil 100 pcs

\begin{tabular}{lc}
\hline \multicolumn{1}{c}{ Nama Akun } & Dalam Satuan $(\mathrm{Rp})$ \\
\hline Biaya Bahan Baku & 5.000 .000 \\
\hline Tenaga Kerja Langsung & 300.000 \\
\hline Overhead Pabrik Variable & 1.200 .000 \\
\hline Kos Produksi & $\mathbf{6 . 5 0 0 . 0 0 0}$ \\
\hline Harga pokok per unit & 65.000 \\
\hline Sumber : Data Olahan (home industry sepatu kulit 2021)
\end{tabular}

3. Produk Sepatu Safety dengan hasil 100 pcs

\begin{tabular}{lc}
\hline \multicolumn{1}{c}{ Nama Akun } & Dalam Satuan $(\mathrm{Rp})$ \\
\hline Biaya Bahan Baku & 9.000 .000 \\
\hline Tenaga Kerja Langsung & 700.000 \\
\hline
\end{tabular}




\begin{tabular}{lc}
\hline Overhead Pabrik Variable & 3.000 .000 \\
\hline Kos Produksi & $\mathbf{1 2 . 7 0 0 . 0 0 0}$ \\
\hline Harga pokok per unit & 127.000 \\
\hline Sumber : Data Olahan (home industry sepatu kulit 2021)
\end{tabular}

Hasil perhitungan harga pokok produksi dengan metode Full Costing

1. Produk Sepatu Kerja dengan hasil 110 pcs

\begin{tabular}{lc}
\hline \multicolumn{1}{c}{ Nama Akun } & Dalam Satuan (Rp) \\
\hline Biaya Bahan Baku & 8.000 .000 \\
\hline Tenaga Kerja Langsung & 500.000 \\
\hline Overhead Pabrik Tetap & 2.100 .000 \\
\hline Overhead Pabrik Variable & 300.000 \\
\hline Kos Produksi & $\mathbf{1 0 . 9 0 0 . 0 0 0}$ \\
\hline Harga pokok per unit & 99.000 (dibulatkan) \\
\hline Sumber : Data Olahan (home industry sepatu kulit 2021)
\end{tabular}

2. Produk Sepatu Sekolah dengan hasil 100 pcs

\begin{tabular}{lc}
\hline \multicolumn{1}{c}{ Nama Akun } & Dalam Satuan (Rp) \\
\hline Biaya Bahan Baku & 5.000 .000 \\
\hline Tenaga Kerja Langsung & 300.000 \\
\hline Overhead Pabrik Tetap & 1.100 .000 \\
\hline Overhead Pabrik Variable & 320.000 \\
\hline Kos Produksi & $\mathbf{6 . 7 2 0 . 0 0 0}$ \\
\hline Harga pokok per unit & 67.200 \\
\hline Sumber : Data Olahan (home industry sepatu kulit 2021)
\end{tabular}

3. Produk Sepatu Safety dengan hasil 100 pcs

\begin{tabular}{lc}
\hline \multicolumn{1}{c}{ Nama Akun } & Dalam Satuan (Rp) \\
\hline Biaya Bahan Baku & 9.100 .000 \\
\hline Tenaga Kerja Langsung & 780.000 \\
\hline Overhead Pabrik Tetap & 2.750 .000 \\
\hline Overhead Pabrik Variable & 320.000 \\
\hline Kos Produksi & $\mathbf{1 2 . 9 5 0 . 0 0 0}$ \\
\hline Harga pokok per unit & 129.500 \\
\hline Sumber : Data Olahan (home industry sepatu kulit 2021)
\end{tabular}

Hasil Perhitungan Harga Pokok Produksi dengan menggunakan metode variable costing dan metode full costing

\begin{tabular}{lccc}
\hline \multirow{2}{*}{ Produk } & \multicolumn{2}{c}{ Harga Pokok Produksi } & Selisih Kedua \\
\cline { 2 - 3 } & $\begin{array}{l}\text { Metode Variabel } \\
\text { Costing }\end{array}$ & $\begin{array}{l}\text { Metode } \\
\text { Costing }\end{array}$ & Full \\
\hline Kerja & 10.500 .000 & 10.900 .000 & 400.000 \\
\hline Sekolah & 6.500 .000 & 6.720 .000 & 220.000 \\
\hline Safety & 12.700 .000 & 12.950 .000 & 250.000 \\
\hline Total & $\mathbf{2 9 . 7 0 0 . 0 0 0}$ & $\mathbf{3 0 . 3 4 0 . 0 0 0}$ & $\mathbf{8 7 0 . 0 0 0}$ \\
\hline Sunn
\end{tabular}

Sumber : data olahan (home industry sepatu kulit 2021) 
Dari data tersebut, dapat dilihat perbedaan antara kedua metode perhitungan harga pokok produksi antara metode variable costing dengan metode full costing. Selisih antara dua metode tersebut yaitu sebesar $\mathrm{Rp}$ 870.000. Perbedaan disebabkan oleh metode perhitungan harga pokok produksi dimana perusahaan memasukan biaya administrasi dan umum, seperti biaya perlengkapan kantor ke dalam biaya overhead pabrik yang menyebabkan perhitungan harga pokok produksi melalui metode full costing lebih tinggi dari pada perhitungan harga pokok produksi dengan metode variable costing. Pada perhitungan metode full costing biaya administrasi dan umum tidak dimasukkan sebagai biaya overhead pabrik, tetapi dimasukkan dalam biaya yang dibebankan ke dalam laporan laba rugi.

Dampak perhitungan dari hasil diatas yaitu dapat mempengaruhi harga jual yang cenderung lebih tinggi, sehingga menyebabkan persaingan antar pasar sejenis sedikit lebih sulit, karena banyak perusahaan lain yang bergerak dibidang yang sama dan menawarkan harga yang relative lebih murah dibanding perusahaan ini, akan tetapi dengan menggunakan perhitungan metode variable costing ini mempengaruhi harga jual perusahaan, sehingga mampu bersaing dengan perusahaan lainnya.

Akan tetapi, dengan hasil wawancara yang sudah dilakukan oleh peneliti, diketahui bahwa banyak pelanggan yang mengatakan bahwa harga di toko sepatu Three Star's masih lebih murah dibanding dengan toko yang lainnya. Hal ini dikemukakan oleh salah satu pelanggan toko Three Star's yaitu Bapak Khoirul yang bekerja di pabrik PT. Primabox Adiperkasa :

"Saya adalah pelanggan tetap di toko Three Star's, saya sangat suka dengan hasil produk dari Three Star's, karena awet, bisa pesan dalam jumlah yang besar maupun sedikit dan juga mempunyai kualitas yang bagus tidak kalah dengan sepatu buatan home industry maupun industry yang lain, dan juga harganya masih relative murah dibanding dengan yang lainnya".

Dari hasil survei dilapangan, peneliti juga menemukan bahwa para pelanggan Three Star's tidak bermasalah dengan adanya harga yang mahal, karena harga menunjukkan kualitasnya. Kualitas dari Three Star's sudah terbukti, sepatu maupun sandal yang dihasilkan oleh Three Star's bisa dibilang awet, hal itu disebabkan karena sepatu dan sandal tersebut selain di beri lem juga di jahit. Dan harga yang mahal itu karena bahan yang dipakai juga mempunyai kualitas yang bagus. Hal ini dikemukakan oleh salah satu pelanggan Ibu Lutfiati :

"Saya beberapa kali memesan sepatu disini, saya merasa puas dengan hasil yang diberikan, sepatu dan sandalnya benar-benar awet, karena selain diberi lem juga dijahit. Harga mahal karena kulaitas bagus saya rasa tidak jadi masalah".

Harga dan kualitas barang juga akan mempengaruhi dari kepuasan pelanggan, ada beberapa orang yang tidak mempermasalahkan harga jika barang tersebut benarbenar mempunyai kualitas yang tinggi, tetapi banyak juga orang yang menginginkan harga murah tetapi tidak masalah dengan kualitas yang rendah, dan ada pula beberapa orang yang menginginkan harga murah kualitas bagus. Semua itu tergantung dari masing-masing konsumen dan kecermatan dalam membeli suatu barang. Jangan sampai konsumen tersebut kecewa dengan barang yang dibeli, karena itu akan menimbulkan 
ketidak puasan oleh konsumen dan dapat menimbulkan stigma buruk bagi produsen atau penjual.

Dari wawancara juga di dapat hasil bahwa rata-rata para pelanggan Three Star's lebih memilih kualitas produk dibanding dengan harga. Karena mereka lebih memilih barang yang awet atau tahan lama, nyaman pada saat dipakai, dari pada harga yang murah tapi tidak nyaman pada saat dipakai dan barang cepat rusak. Pernyataan tersebut dikemukakan oleh salah satu pelanggan Three Star's Bapak Arifki:

"Kalau menurut saya pribadi, saya lebih memilih membeli satu barang yang mahal tetapi tahan lama, dan nyaman dipakai dari pada harus membeli berkalikali dengan harga yang murah tapi kualitas rendah."

Semua itu kembali lagi kepada masing-masing konsumen, lebih kepada individu masing-masing. Karena kepuasan pelanggan juga dapat di ukur dari manfaat dan biaya yang di peroleh atau dikeluarkan.

\section{Kesimpulan}

Terdapat perbedaan antara menggunakan metode variabel costing dan metode full costing, dari hasil data yang diperoleh sebaiknya toko Three Star's menerapkan metode variabel costing karena perhitungan harga pokok produksi, penentuan harga jual dalam harga pokok produksi dan biaya per unit lebih rendah dibanding dengan menggunakan metode full costing. Para pelanggan toko Three Star's juga tidak mempermasalahkan tentang harga yang mahal, karena sudah terbukti bahwa produksi dari toko Three Star's memiliki kualitas yang sangat bagus, sehingga membuat para pelanggan merasa puas. 


\section{Bibliography}

A, H. M. (2019). Manajemen Pemasaran Syariah. Edisi 1 (UPP STIM Y).

Buchari, A. (2011). Manajemen pemasaran dan pemasaran jasa. Bandung: Alfabeta.

Bungin, B. (2019). Metodologi penelitian kualitatif: Aktualisasi metodologis ke arah ragam varian kontemporer.

Fauzan, F. (2019). MANAJEMEN PEMASARAN SYARIAH: Sebuah Pengantar. Bildung.

Fitria, A. (2018). Analisis Proses Produksi Pendekatan Harga Pokok Produksi (Studi Kasus di Home Industri Lanting Bumbu Mekar Sari Desa Lemahdhuwur Kec. Kwarasan. Kab Kebumen). IAIN Purwokerto.

K, D. P. . dan S. B. (2014). Akuntansi Biaya. Edisi 2 (IN MEDIA).

Kotler, P., \& Amstrong, G. (2012). Principles of Marketing Global. USE: Pearson Education, 6, 47-48.

Mulyadi. (2015). Akuntansi Biaya 1. Edisi 5. UPP STIM YKPN.

Mulyanto Veri Arti. (2017). Analisis Perhitungan Harga Pokok Produksi Untuk Menentukan Harga Jual Produk dengan Metode Mark-Up pada UD. BUDI TUKUL. Universitas Nusantara PGRI.

Philip, K., \& Keller, K. L. (2012). Manajemen Pemasaran Edisi 14, Global Edition. Pearson Prentice Hall.

Rizqi, R. (2018). Penentuan Metode Perhitungan Harga Pokok Produksi Pada Home Industri Sepatu Kulit Bu Imas. Prosiding Festival Riset Ilmiah Manajemen Dan Akutansi: FRIMA, 1091-1096. 